suddenly ill with laryngeal symptoms and with urgent inspiratory dyspnœa. It was playing about previously. There was no appreciable cause. When I saw it, shortly afterwards, the child was greatly distressed; its voice was gone, and death seemed imminent. Tracheotomy was at once performed, and gave instant and complete relief. A few days later attempts to remove the tube were commenced, but were quite unsuccessful. The child died in convulsions, and at the autopsy a small piece of eggshell was found adhering to the side of the larynx.

Case 2. Sudden Dyspnoea; Fishbone suspected as the Cause: Tracheotomy; Measles; Death; Autopsy; Impaction of Bone in the Glottis. - A little boy, eighteen months old, taken with sudden dyspnoea while or shortly after eating fish for dinner. The cause was immediately suspectedviz., that he had swallowed a fishbone. A most careful search with the finger was made in the pharynx and upper part of the larynx, as far as possible, but without success. Tracheotomy had to be performed hurriedly. After its completion another search for the suspected bone was made, but with no better success; the tube was then inserted. The boy did well after the operation, except that his temperature remained high. Frequent attempts to remove the tube were made. He could neither phonate nor inspire through the glottis. An attempt to examine with the laryngoscope failed. A catheter could be passed into the mouth through the tracheal wound, but the child continued quite unable to breathe without his silver tube. The question of thyrotomy and other plans of treatment were discussed. The child's age was an element of great difficulty. However, about three weeks after the tracheotomy the child took measles, which was very prevalent at the time, and died of lung complications. At the post-mortem examination the glottis was found quite closed, with a long slender fishbone between the cords. The upper extremity of the bone projected into the pharynx, and it seemed a little remarkable that its presence was not detected by the finger when search was made for it.

These cases are of interest as showing the difficulties which beset diagnosis as well as treatment. In such cases the number of failures will certainly be lessened if the treatment of feathering out the glottis be practised as a matter of routine in all cases. But whether this treatment be adopted or not, it may be laid down almost as a rule of surgery when tracheotomy has been performed on account of a foreign body, that the persistence of the symptoms points to a persistence of the cause; little, therefore, is gained by waiting. The larynx should in all cases be examined, both from the wound and from the mouth, to make sure that the foreign body is not impacted in some part or other of the larynx, and further attempts must be made to remove it.

(To be continued.)

\section{A NEW LONG SPLINT FOR FRACTURE OF THE THIGH.}

BY GEORGE SHIRRES, M.B., C.M.

IATE RESIDEXT ASSISTANT-SURGEON, ROYAL INFIRMARY, ABERDEEN.

IT has often occurred to me while putting up cases of fractured femur in Liston's long splint that if the splint could be lengthened after it had been adjusted to the limb, it would be an improvement; and it seemed that such an object might be attained if the splint were constructed of two pieces or slides fitting into one another. That by such means a splint might be made which could be altered to any length so as to suit a child or an adult, and which after it had been adjusted to the limb might be still further lengthened. With these ends in view a splint has been devised of which the accompanying engraving (kindly supplied by Messrs. Arnold and Sons) gives a very good idea. This splint consists of two iron slides freely movable upon one another. The lower slide having its edges inverted so that the upper may fit into it. It is three feet long by three and a quarter inches broad. The upper slide has on its inner surface a strip of iron on each side; these when the slides are fitted into one another form a hollow along which iron plates may more. Each slide has a long narrow slit passing up its centre, on the sides of which supports may be clamped. Each slide is provided with a support; that of the upper slide consists of a brass bar in the form of a screw half an inch long. The top of this screw expands into a flat circular head with a hole in the centre. The foot of the screw passes freely through the centre of a circular iron plate one inch and a quarter in diameter, and is then riveted into the centre of another plate of the same kind. A thumbscrew turning around the brass bar acts on the upper plate, pressing it down. The brass bar passes along the inside of the narrow slit in the upper slide, the edges of the slit passing between the two iron plates which may by means of the thumb-screw be firmly clamped on to it at any part of its length. The lower support is nearly similar in shape to the upper one, and may in the same manner be firmly clamped on to any part of the slit in the lower slide. To the head of this lower support a screw, one quarter of an inch in diameter and nine inches long, is attached; the upper end of this screw passes through the hole in the centre of the head of the upper support. A disc one inch and an eighth in diameter travels along the screw between the two supports and catches the upper one. The thumb-screw of the lower support is provided with a shoulder which passes through the slit in the upper slide when the two slides overlap one another. The lower plate on the upper support and the upper plate on the lower one can be moved along the hollow between the two slides (formed by the two iron strips on the upper slide). So that the splint may be broken at any part by clamping the supports and connecting them by the long screw and disc. By moving the upper slide along the lower and clamping the supports when necessary, the splint may be made long enough to suit any patient, and when the splint has been adjusted to the requisite length it may be still further lengthened by turning the dise on the screw. The upper end of the splint is rounded outwards so as to fit into the axilla, and is provided with holes for the perineal band. There is an aperture in the splint four and a half inches from the lower end to accommodate the external malleolus. There is also a crossbar fixed to the lower end of the splint acting as a foot-piece, which may be fitted on at either edge of the splint, so that it may be used for either side.

The advantages which I believe this splint to possess are:- It may be set at any length so as to suit a child or an adult. After the splint has

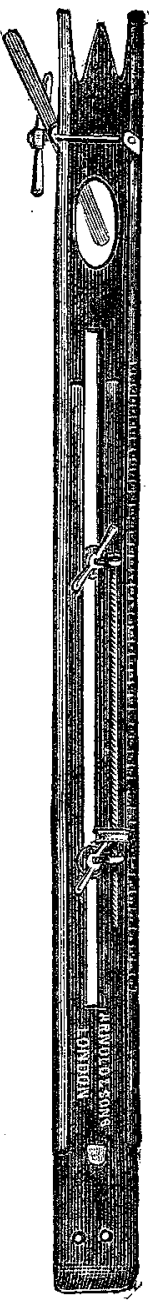
been clamped at the requisite length and adjusted to the limb, extension may be put on by simply turning the disc on the screw so as to do away with the necessity of tightening the perineal band, forming at the same time a very easy and practical method of extension. In transport and on board ship, and in circumstances where weights cannot be used, the gradual extension, which can be produced by means of this splint, will, 1 believe, be found particularly valuable.

In working out this splint I have to thank Professor Ogston, of Aberdeen, for many valuable suggestions. The splint may be had from Messrs. Arnold and Sons, West Smithfield, London. Tillotson-place, W.C.

\section{CASE OF}

\section{VERTEBRO-MENINGEAL RHEUMATISM.}

\section{BY J. E. BLOMFIELD, B.A. OXON.,} R.DOCLIFFE TRAVELLING FELLOW.

THE case of which the following is a short account occurred in the practice of Professor Jaccoud, at the Hôpital de la Pitie, Paris. Taking into consideration its rarity, and the facility with which the diagnosis of rheumatism could be established, it is worthy of wider notoriety than is afforded by being the subject of a clinical lecture, and is certainly interesting as a contribution to our knowledge, which is far from complete, of the various phenomena of rheumatism. The patient was a man of robust appearance, forty years of age, who had enjoyed good general health until the 24 th of January of last year, when he presented 
himself at the hospital complaining of pain in the region of the neck, of the shoulders, and in both upper extremities. This painful state was not produced by degrees, but had arisen suddenly without assignable cause. The pain was violent, and, according to the description of the patient, it seemed as if his arms were being twisted off. The slightest movement increased the pain. The seat of the pain was not localised, but it seemed to shoot down the arm. The neck was held quite rigid by the contractions of the muscles, so as to prevent any movement of the cervical vertebræ, and this part of the spinal column was bent backwards so as to constitute a slight opisthotonos.

On examining the arm there was nothing seen to account for the pain. There was no redness or swelling, and the joints themselves were quite free from any suspicion of disease; but it was possible to discover that certain areas of the skin were devoid of sensibility; and, further, that these points were spontaneously painful - that is to say, the patient presented the phenomena of anesthesie douleureuse. When seen by Professor Jaccoud it was discovered that the region of the spine marked by the fifth, sixth, and seventh cervical vertebræ was very tender. Pressure over this region increased not only the local pain, but also the pain down the arms; and taking into consideration the character of the pain and the local tenderness, the professor came to the conclusion that the lesion was central, and, further, that it was rheumatic, because there was no history of a blow or other injury. There was no evidence of syphilis or tubercle; in fact, he considered it as a case of articular rheumatism of the upper part of the spinal column, involving the meninges; and, in accordance with this opinion, ordered a treatment of sodium salicylate. But to complete this diagnosis there was one point wanting, and that was the temperature. On the day of the examination the patient's temperature was normal, but in the evening it rose to $39 \cdot 4^{\circ} \mathrm{C}$, thus supplying the fact which was missing. The correctness of the diagnosis was well illustrated by the treatment, for the effect of the sodium salicylate was marked and immediate. The pain diminished, and with it the rigidity; and by the end of February the patient left the hospital practically cured, only a slight rigidity of the neck remaining, obviously due not to the muscular contraction, but to the articular lesion. But in the first fortnight of March he presented himself again at the hospital in exactly the same condition as before, with the addition that the lower limbs were also affected in a similar manner. Soon, however, another manifestation showed itself, which is of great importance as adding another item of support to the diagnosis, and that was the tumefaction and redness in the left knee and ankle.

The patient was now a hopeless cripple in bed, not daring to move a limb because of the pain, which, as before, was much exaggerated by any movement, though when encouraged to make the requisite effort it was found that perfect power over the muscles was retained. This, however, did not last long, for towards the end of March it was found that there was a loss of ability to move the limbs however much the patient tried; in fact, there was complete akinesia and anresthesia of all four extremities. It is an interesting fact that this loss of motion appeared first in the arms and afterwards in the lower limbs. The treatment adopted at this time was iodide of potassium, but no marked benefit was noticed, and the patient continued in much the same state during April, with the exception that defecation and micturition became affected, and the patient passed his motions under him unconsciously

In the month of May mercurial inunctions night and morning were added to the previous medication, not with the idea of counteracting any syphilitic taint, but because of the well-known property of mercurials of removing plastic deposits, to which his troubles were attributed, and some slight improvement seemed to be gained. In the month of June the patient was again in much the same state, except that an ulcer over the sacrum was added to his other troubles. In September, during the absence of Prof. Jaccoud, the treatment was changed and strychnia was given, and soon after this a sign of improvement appeared, due probably not to the change of drug, but to the salutary influence of time, aided possibly by the previous medication. Whatever was the cause the power of movement began to return, first, in the upper limbs, and then in the lower, and at the same time the anæsthesia disappeared and gave place to a degree of hyperasthesia, and with these improvements the ulcer on the sacrum began to heal. The muscles were found to have preserved their electric reactions in a normal state, despite the time that they had remained useless.

\section{A}

\section{HOSPITAL PRACTICE, BRITISH AND FOREIGN.}

Nulla autem est alia pro certo noscendi via, nisi quamplurimas at morborum et dissectionum historias, tum aliorum tum proprias collectas habere, et inter se comparare.-MORGAGNI De Sed. et Caus. Morb. lib. iv. Procmium.

\section{LONDON HOSPITAL.}

TRANSVERSE FRACTURE OF THE PATELLA; ASPIRATION OF THE JOINT; SUPPURATION; ANTISEPTIC INCISIONS INTO THE JOINT, FOLLOWED A FEW DAYS CATER BY WIRING OF THE FRAGMENTS; RECOVERY; REMARES.

(Under the care of Mr. RIvington.)

Fracture of the patella is an injury which requires both care and skill in its treatment, and the fact that there is still so much difference of opinion in the profession as to which is the best method to pursue in such cases is an additional proof of this. The methods employed are numerous, and Mr. Rivington's case was one in which it was necessary to use more than one of these methods, and in which there is every prospect of a strong limb and useful joint being secured to the patient.

Charles A - aged fifty-eight, was admitted on the 29th December, 1883. He had fractured his left patella transversely a little below the middle, by falling on the kerb. There was a great deal of effusion. A back splint and ice-bag were applied. Two days afterwards the housesurgeon made an attempt to bring the fragments together with strapping. On Jan. 11th, there being still much swelling and effusion, Mr. Rivington aspirated the kneejoint, dipping the trocar and cannula in a strong solution of carbolic acid, and using the spray to make "assurance doubly sure." Only two drachms of mingled blood and serum could be obtained. Antiseptic dressing and an icebag were applied. On the 16th the house-surgeon tried to reduce the distance between the fragments with Malgaigne's hooks inserted into strapping and gutta-percha, and the separation was diminished about a third of an inch. This procedure did no good, as it increased the effusion, and the hooks were accordingly removed. A week later, finding that pus was oozing from the puncture made by aspiration, Mr. Rivington had the steam spray turned on and an anæsthetic administered, and he opened the knee-joint freely, making an incision on each side of the patella, removing a good deal of clot from the joint, washing it out, and inserting drainage-tubes. Finding at the end of the week that the case was doing well, he had the patient in the operating theatre, and cut down on the patella by means of a vertical incision in the middle line, removed all the vascular granulation tissue uniting the fragments, scraped the fractured surfaces, taking away projecting edges with cutting pliers, and wired the fragments together. The wire was beaten down on to the patella, the lateral openings enlarged, and drainage-tubes inserted. The operation was performed with all antiseptic precautions, and a back splint applied on its completion. On the 5th the wounds were redressed; there was very little discharge. On the 12 th the drainage-tubes were removed, and on the 22 nd the openings into the joint had closed. On March 7th antiseptics were discontinued. On the 10th the wounds had healed. On the $22 \mathrm{nd}$ the limb was taken off the splint. There was considerable inflammatory thickening round the knee-joint, and it was slightly painful as well as stiff. On the 25 th the patient was allowed to get up. Change from the horizontal to the vertical position produced œdema of the limb. The patient, naturally a spare, delicate-looking man, was in fairly good health, although weakened by his long illness. He could not bear any weight on the limb. By April 7 th he was able to walk a little, but his feet swelled when he was up, and more especially the left foot. He was ordered an elastic bandage. He had very little movement in the joint, and no attempt was made to remove the stiffness for fear of breaking down the union of the fragments 